\title{
Female Gaze Behaviour, Status and the MENSTRUAL CyClE: AN EXPLORATORY STUDY
}

\author{
Martin A. Sharp \& Geordan E. Hamilton \\ School of Health and Life Sciences, Glasgow Caledonian University, Glasgow, UK. \\ martin.sharp@gcu.ac.uk
}

\begin{abstract}
Whilst not explaining all social behaviour and organisation, dominance is nevertheless an important dimension of human social interaction. It has been hypothesized that gaze behaviour reflects the dominance hierarchy of primate groups and several studies have demonstrated that cues associated with social status also influence human gaze. These studies overwhelmingly involve male participants and sex differences in coalition formation, status seeking, risk taking and dominance-related behaviour have all been explained by the fact that males needed to compete for mates while females supposedly did not. Indeed, until comparatively recently it was thought that dominance contests were of little consequence for females. However, there is increasing evidence to suggest that competitiveness is useful for females and there are attendant benefits conferred upon those with high status. Thus, it is important to understand these status-gaze relationships in women. Sixty heterosexual, caucasian female participants (mean age $=22.1, S D=3.16$ ) competed in a dyadic non-physical status encounter (woodblock game Jenga). Dyads were unknown to each other and matched by menstrual phase (follicular/luteal) or contraceptive use. Winners were congratulated and received $£ 5$ to accentuate status disparity. In the two minutes following competition participants sat apart but in sight of each other. The investigator left the room and gaze behaviour was recorded by video camera. The length of time each participant spent looking at their opponent was related to competition outcome: winners $(M=3.96, S D=1.72)$, losers $(M=7.34, S D=4.32)$. There were main effects for outcome, $F(1,54)=22.47, p<0.0001$ and menstrual phase/contraceptive use $F(2,54)=5.34, p=0.008$. Follicular and Luteal phase did not differ from each other significantly. The interaction between outcome and menstrual phase/ contraceptive use was significant, $F(2,54)=8.75, p<0.001$, with contraceptive use reversing the findings of longer gaze time in the loss condition in normally cycling women. Our results support the hypothesis that female gaze behaviour is responsive to the outcome of status encounters.
\end{abstract}

Keywords: Gaze behaviour, status, female, menstrual cycle, contraceptive pill. 


\section{INTRODUCTION}

With its emphasis on male agency and female passivity Darwin's theory of sexual selection (1871) remains controversial (Gowaty, 1997). Kemper (1990) proposes that the transformation of gender roles renders the view of women as essentially pacific, retiring, and lacking in the psychological need for dominance, intellectually unsustainable. Sex differences in behaviours such as coalition formation, status-seeking and risk-taking have all been variously explained by the fact that males needed to compete for mates while females did not (Geary, 2010; Mazur, 2005). So, the presumed greater variability of males, with a capacity to contribute to the production of more offspring has, it is argued, driven competition (Bateman, 1948; Daly \& Wilson, 1983; Fausto-Sterling, 1992), with Campbell seeing 'women's lesser willingness to escalate competition to direct aggression as arising out of their particular biology rather than from conformity to cultural expectations of femininity' (2004, p.643). Nevertheless, Hrdy (1999) suggests it would be a mistake to think that the female of many species could afford to be unaggressive, either in defence of territory or offspring.

Gowaty wrote 'I consider the long-standing theoretical primacy of male-male competition to be one of the most potentially misleading notions in evolutionary biology' (1992, p.229). And yet, until comparatively recently, it was thought that females had little variance in reproductive success, rendering dominance contests of negligible significance (Fausto-Sterling, 1992). There is, however, growing evidence to indicate that in often subtle ways competitiveness and dominance are useful for females too (Hodge, Manica, Flower, \& Clutton-Brock, 2008; Hrdy, 1999; Pusey, Williams, \& Goodall, 1997). For example, in marmosets, proximity of dominant females may suppress ovulation in subordinate animals (Clutton-Brock \& Harvey, 1977; Wasser \& Barash, 1984). Dominance rank in female chimpanzees has been found to correlate positively with reproductive success (Wittig \& Boesch, 2003) and dominant females in a variety of species are reported as having more offspring, their female offspring reach reproductive age quicker and have greater infant survival (Ellis, 1995; Grant, 1994).

In describing the multi-dimensionality inherent in the organisation and maintenance of small group structure in primates Mazur (1973) suggests a number of modes of interaction which may be independent of status hierarchy. Consequently, although not intended to explain all social behaviour and organisation, in both animals and humans, dominance is an important dimension of social interaction (Brewer \& Caporael, 1990; Cosmides \& Tooby, 1987). Indeed, the emergence of dominance hierarchies in small groups is documented across every culture throughout history (Dunbar, 1988). Whilst several authors have investigated the formation of dominance hierarchies, comparatively little research has focused on gender differences (Schmid Mast, 2001, 2002; but see Tiger \& Fowler, 2007), even though the stereotypical view of men being inclined to form hierarchical dominance structures while women build egalitarian ones is widely accepted (de Waal, 1986; Frauendorfer et al., 2014; Gilligan, 1982; Schmid Mast, 2002). And, although contrary to the findings of earlier studies, Cashdan (2004) has argued persuasively that, whilst female hierarchical structures may take longer to become stable, men and women may be equally concerned with forming these structures within a group setting. 
Whilst far from the uncomplicated relationship that is often claimed, high status in hierarchical social structures is generally regarded as resulting in disproportionate access to resources which can subsequently increase mating opportunities (Buss, 2014; Hawley, 1999). There are, however, concomitant issues relating to the physiological consequences of stress. In some animal species being subordinate is stressful (Abbott et al., 2003; Blanchard, Sakai, \& McEwen, 1993). Subordinate males may, for example, experience significantly higher levels of glucocorticoids at rest and present an endocrine response that is both smaller and more sluggish than in dominant animals (Sapolsky, 1982). Resultantly, where there is disruption of the hypothalamic-pituitary-adrenal (HPA) axis an individual can be exposed to greater risk of infection and illness through impairment of the immune system (Herbert \& Cohen, 1993; Sapolsky, 2002). However, this association between negative consequences and social subordination is not straightforward and largely species specific. Subordinate and lower ranking marmosets, for example, show no physical or psychological stress due to their rank within the social group (Abbott et al., 2003). In wild dogs, by contrast, occupying a position of dominance is more physiologically demanding (Creel, 2001; Goymann \& Wingfield, 2004). In humans, the relationship between stress and status ismore difficult to untangle because of the relative psychological weight and meaning people attach to status events (Lazarus \& Folkman, 1984).

There is overwhelmingly more emphasis in the literature on male status whilst far less has been written about the agentic aspects of women. But, any simple analogy from males cannot be assumed (Hrdy, 2009; Tiger \& Fowler, 2007). Thus, in human females the relationship between stress and small-group hierarchy remains ambiguous. Where females do find themselves in situations of status disparity Campbell (1999) has suggested that those in a subordinate position are likely to try and minimize feelings of stress by attempting to form social networks. This idea is leant support by the tend and befriend hypothesis, characterized in part by its emphasis on individuals during times of stress befriending those in close proximity as a strategy for increasing the likelihood of survival (Taylor et al., 2000).

As humans are social beings, paying attention to others through gazing enables them to monitor intentions, actions and behaviour (Emery, 2000; Foulsham, Cheng, Tracy, et al., 2010; Hayhoe \& Ballard, 2005). Certainly, humans have an involuntary tendency to communicate through gaze behaviour (Bjorkgvist, Lagerspetz, \& Kaukiainen, 1992; Langton, O’Malley, \& Bruce, 1996). In the context of hierarchy there is evidence to suggest that gaze is attuned to threat-vigilance and responsive to status ranking (Koch, et al., 2010; Leffler, Gillespie \& Conaty, 1982; Mazur, 2005; Mazur \& Booth, 1998). However, findings vary by species and are often contradictory. On one hand, subordinates have been found to focus more visual attention towards a dominant individual (Dovidio et al., 1988). Contrastingly, low social rank has been linked with submissive behaviour and eye-gaze avoidance where subordinates will not look directly at the dominant individual (Gilbert, 1993; Harper, 1985; Setchell \& Wickings, 2005). The relationship between gaze behaviour and status disparity in human females is rendered more difficult to interpret when menstrual cycle effects and oral contraceptive use are considered. Several parameters of female behaviour and cognitions have been shown to alter with menstrual phase (Buser, 2012; Gangestad et al., 2004; Lübke \& Pause 2014; Mastaka, \& Shibasaki, 2012; Piccoli, Foroni, \& Carnaghi, 2013). Although 
evidence regarding the effects of menstrual phase on female competitiveness is equivocal Buser (2012) intrasexual competition appears to be related to levels of circulating testosterone (Hahn, Fisher, Cobey, et al., 2016) and this hormone fluctuates across the menstrual cycle (Al-Dujaili \& Sharp, 2012). Furthermore, elevated progesterone levels during the menstrual cycle have been associated with higher intensity ratings of faces displaying fearful expressions (Conway et al., 2007) and whilst fluctuations of estrogen and progesterone are not entirely eradicated when administering hormonal contraception, natural bodily excretion of these hormones reduces drastically in woman who use the pill (Rivera, Yacobson, \& Grimes, 1999). Consequently, in an exploratory study we sought to ascertain the effects of menstrual phase, oral contraceptive use and status disparity following non-physical dyadic competition on naturalistic gaze behaviour. Our hypotheses were: H1 - Gaze behaviour will vary by competition outcome; H2 - Gaze behaviour will vary according to menstrual phase and contraceptive use.

\section{METHOD}

\section{Participants}

Sixty heterosexual Caucasian female subjects aged between 18 and 31 years $(M=22.1, S D$ $\pm 3.16)$ competed in a between subjects, dyadic, non-physical status encounter involving the woodblock game Jenga (Copyright Hasbro, 2003). Forty of those participants selfreported regular menstrual cycles, defined as three consecutive cycles lasting between 27-34 days $(M=28.7$ days, $S D \pm 1.36)$ and twenty were administering an oral contraceptive (combined pill containing estrogen and progestogen). Ethical approval was obtained from the university School of Health and Life Sciences Ethics Committee.

\section{Procedure and Materials}

Competition dyads were unknown to each other and matched by menstrual phase (follicular/luteal) or contraceptive use, so 10 pairs competed whilst in the follicular phase, 10 pairs in the luteal phase and 10 pairs were administering the contraceptive pill and took part in the competition between days 4 and 20 of contraceptive administration in order to avoid undue fluctuations in endocrine profile in the 7 days during which the pill is not administered (Rivera, Yacobson, \& Grimes, 1999). The study was conducted in a 16'x16' dedicated observation lab. Each dyad played one game and all sessions took place between 1:00pm and 5:00pm. To both increase salience and accentuate status disparity, upon completion of the competition winners were enthusiastically congratulated and were handed $£ 5$ in full view of the losers who were ignored. In the two minutes following competition, participants sat apart but in sight of each other and were asked not to use mobile phones or speak with each other. The investigator made excuses and left the room. Gaze behaviour was recorded using a tripod-mounted digital video camcorder (Canon Legria HF R56). The length of time participants spent looking at each other was ascertained by two independent observers (>99\% agreement). Criteria for opponent-directed gaze were that participants must have looked directly at their opponent and not simply in their general direction. 
Sharp M.A. \& Hamilton G.E.: Female Gaze Behaviour, Status and the Menstrual Cycle Human Ethology Bulletin 32 (2017)1- Proc. of the XXIII Biennial ISHE Congress: 29-41

\section{RESULTS}

Time spent looking at the opponent (in seconds) across the two-minute postcompetition observation period by outcome and menstrual phase/contraceptive use is reported in table 1. Participants in the loss group gazed significantly longer at those in the win group in both follicular and luteal menstrual phase. This was reversed with the oral contraceptive group, where gaze behaviour under both win and loss conditions did not differ significantly. Participants in all groups almost never stared at each other simultaneously, but glanced when their opponent was averting their gaze.

Table 1: Mean and SD for gaze behaviour (seconds): outcome by condition ( $\mathrm{n}=60)$.

\begin{tabular}{lcc}
\hline Condition & \multicolumn{2}{c}{$\begin{array}{c}\text { Outcome } \\
\text { Mean (SD) }\end{array}$} \\
\hline & \multicolumn{3}{c}{ Win } & Loss \\
Follicular Phase & 3.57 & 10.35 \\
& $(1.32)$ & $(4.61)$ \\
Luteal Phase & 3.95 & 7.80 \\
& $(2.17)$ & $(2.74)$ \\
Oral Contraceptive & 4.37 & 3.89 \\
& $(1.64)$ & $(2.81)$ \\
\hline
\end{tabular}

A two $\mathrm{x}$ three factorial ANOVA was conducted to test the main effects of gaze time and menstrual phase/contraceptive use and the interaction between them on gaze behaviour (see figure 1). The main effect for gaze time yielded an $\mathrm{F}$ ratio of $F(1,54)=22.47, p<$ 0.0001 revealing a significant difference between win $(M=3.96, S D=1.72)$ and loss $(M$ $=7.34, S D=4.32)$. The main effect for menstrual phase/contraceptive use yielded an $\mathrm{F}$ ratio of $F(2,54)=5.34, p=0.008$ revealing a significant difference between follicular/ luteal phase $(M=6.42, S D=4.03)$ and oral contraceptive use $(M=4.13, S D=2.25)$. Follicular and Luteal phase did not differ significantly from each other. The interaction between outcome and menstrual phase/contraceptive use was significant, $F(2,54)=$ 8.75, $p<0.001$. A planned comparison using one-way ANOVA to test differences between the win condition groups was non-significant. However, the loss groups were significantly different, $F(2,29)=8.67, p=0.001$. Post hoc comparison using Sidak revealed that gaze time in the oral contraceptive group differed significantly from follicular and luteal $p<0.001$ whilst follicular and luteal were not significantly different from each other. 


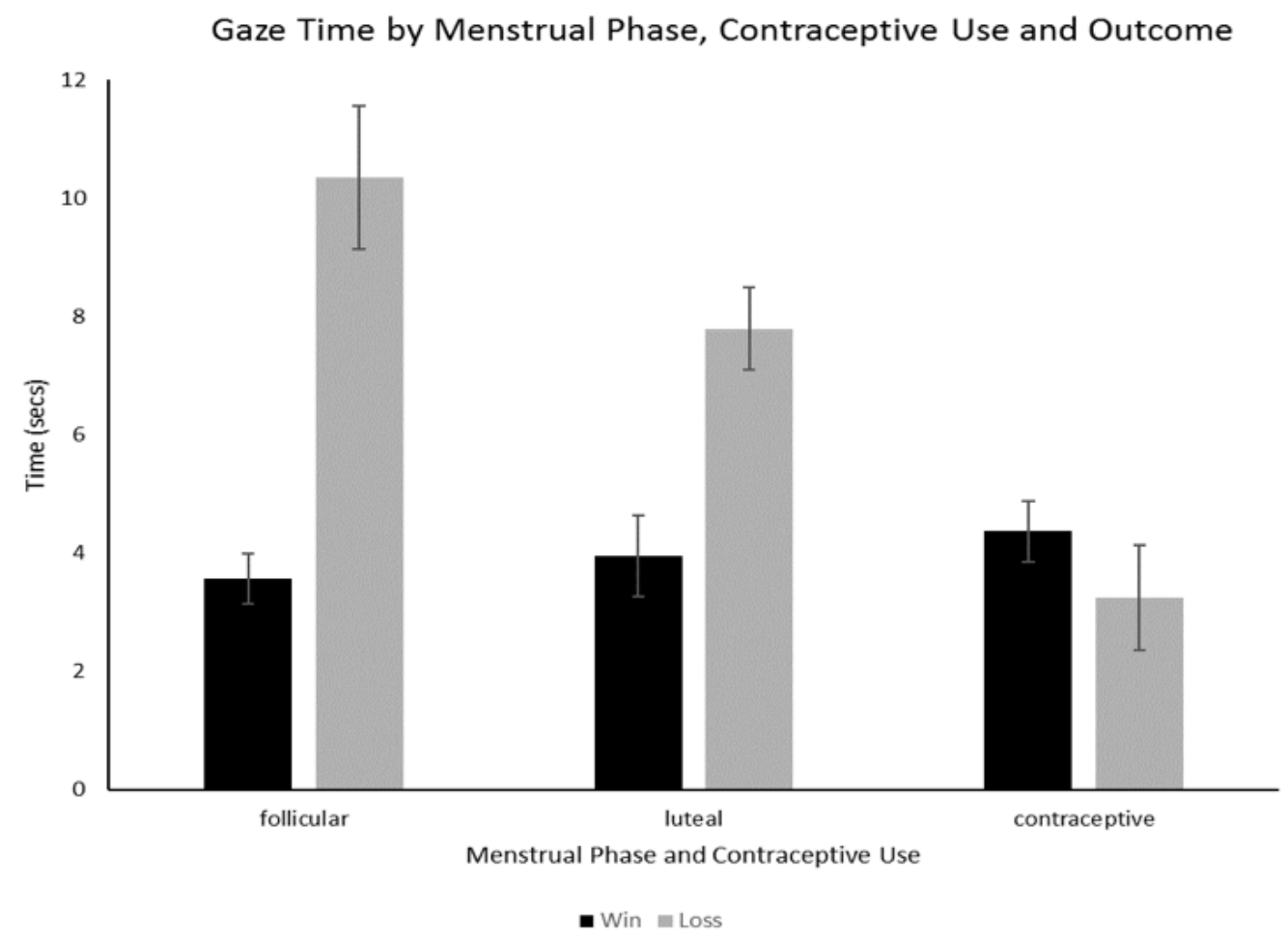

Figure 1: Overall gaze time by menstrual phase, contraceptive use and outcome, mean \pm SEM, $(n=60)$.

\section{DISCUSSION}

Our results are consistent with an attentional gaze system that, in women, is responsive to status disparity. Winners in both follicular and luteal phases of the menstrual cycle gazed in total for a significantly shorter time than those in the losing group. Menstrual phase did not exert an effect at a level reaching statistical significance. In contrast, the findings were reversed with those participants in the oral contraceptive group where there was a lower level of gaze behaviour in the loss group and no significant difference between winners and losers.

Previous literature across a range of species is equivocal on the direction and characteristics of gaze behaviour in relation to status disparity. In some cases, subordination in a social interaction has been found to result in eye-gaze avoidance (Gilbert, 1993; Harper, 1985). One explanation for why this might be proposes that individuals are believed to avoid eye-contact as a result of shame due to losing rank or becoming subordinate (Wicker, Payne, \& Morgan, 1983). However our findings, that normally cycling women in the loss group gazed longer at winners, do not lend support to this position. Nor to the findings that dominant individuals will look longer at subordinate individuals in dyadic encounters (van Honk et al., 1999). However, our findings are supportive of Dovidio et al. (1988) who found an individual who is subordinate will focus visual attention towards a more dominant individual. In line with this view, Campbell (1999) has suggested that the initial response by females following a competitive situation is the formation of social networks as an effort to reduce the 
feelings of stress. Our findings conceivably provide support for this position, where longer gazing time in both luteal and follicular phase (but not in the oral contraceptive group) could be interpreted as an appeasement gesture.

Sade (1973) informs us of the comparative ease with which it is possible to observe and to quantify social dominance in non-human primate species. Although this is due to the limited stereotyped motor patterns used to signal aggression, more important is the highly ritualised fighting behaviour; a style of interaction which enables winners and losers to be identified unambiguously. However, the concept of victory and defeat in humans may be more problematic. Humans appraise and interpret the events in their lives, so that winning becomes a relative judgment representing a subjective experience. In this regard, Schultheiss et al. (1999) suggested that '...personality factors may moderate individuals testosterone responses to succeeding or failing at a dominance contest. Specifically, the strength of an individuals need for dominance or status may play a crucial role in how the individual responds hormonally to a dominance outcomes' ( $p$. 234). Several other authors have also considered similar possibilities. Salvador et al. (2002), for example, suggested that complex psychological processes related to emotional and/or cognitive interpretation of the situation may be more important than the outcome itself. Hence, it is possible that 'winners' in the current study gazed less as they felt awkward or uncomfortable following the enthusiastic congratulations from the experimenter.

As no significant effect was found for menstrual phase on gaze behaviour no clear-cut additional support is provided for the findings that menstrual phase will affect the visual attention of women (Conway et al., 2007; Mastaka \& Shibasaki, 2012). Figure 1. illustrates that in the loss group for normally cycling women follicular and luteal did appear different although not at a level reaching significance. However, we would be wary of overstating our case or contradicting other research findings as our measurement of menstrual phase was self-report and employed only the broadest categories of follicular and luteal.

We were puzzled and intrigued by the findings of participants administering oral contraceptives. Those in the win group did not differ significantly from those in the follicular or luteal phase but there was a large effect on those in the loss group whose gaze behaviour was almost eradicated in comparison with normally cycling participants. Our initial reaction was that the oral contraceptives were perhaps acting in the manner of a chemical cosh; that they were rendering losing participants passive in the face of status disparity, or at least causing them to be seemingly unconcerned by that disparity. However, the opposite interpretation appears just as valid. That those in the loss group spent less time looking at their dominant partner because they were no longer intimidated or fearful and so were actually more empowered. Frustratingly, our data do not allow us to pursue these interpretive positions further.

We speculated by what mechanism the oral contraceptive might be operating. Although, the combined oral contraceptive minimizes fluctuations in both estrogen and progesterone (Rivera, Yacobson, \& Grimes, 1999) it also impacts upon circulating levels of 'free' testosterone $(\mathrm{T})$. This occurs because levels of sex hormone binding globulin (SHBG) increase unpredictably. As Guay (2002) notes, 'birth control pills will not only increase SHBG but decrease ovary's production of hormones, especially androgens' (p.S84). High relative levels of T have been shown to reduce fear threshold in 
heifers (Boissy and Bouissou, 1994) and $\mathrm{T}$ administration has been shown to be responsive to social threat in human females (Hermans, Ramsey, \& Van Honk, 2008). As Al-Dujaili \& Sharp (2012) have previously used the same non-physical experimental paradigm (Jenga competition) to demonstrate that $\mathrm{T}$ falls in the loss group of female status competition we have some confidence the same result might happen here (although temporal patterning of $\mathrm{T}$ reactivity in bio-behavioural studies is complex). Further support is provided by Cobey et al., (2015) and Zimmerman (2015) who report that women using hormonal contraception were found to have lower levels of $T$ than those who were regularly cycling. Consequently, we would expect that low levels of $\mathrm{T}$ might be expected to enhance anxiety and fear. But, if this were the case we would expect to see those participants in the loss group gazing at winners significantly more than if they were normally cycling. And yet, we found exactly the opposite.

As our study was exploratory we recognize a number of limitations and signal caution when interpreting the findings. Our menstrual phase categories were broadly drawn and relied upon self-report. This is not entirely unproblematic because of the potential for differences in days of ovulation and irregularity in menstrual patterns (Alliende, 2002; Macrae et al., 2002; Penton-Voak \& Perrett 2000). There is evidence to suggest that in dominance-oriented situations studying dyadic encounters, as we did, is useful (Mazur et al., 1980; Lamb, 1986). However, Ridgeway \& Diekema (1989) suggest that focusing on the group networks is beneficial and Campbell (1999) reinforces this, especially within a female population. Finally, we did not control for relationship status which has been shown to have impact upon $\mathrm{T}$ levels and competitiveness, although the relationship is far from straightforward in women (Cobey, Klipping, \& Buunk 2013; Cobey et al., 2015; Kuzawa, Gettler, Huang, \& McDade, 2010; van Anders \& Watson 2006).

To conclude, it would be of value if future studies were to explore the chronobiological reactivity of not only progesterone, but cortisol and T. These hormones sit within an inter-connected latticework of influence and have all been implicated to some extent in status-related gaze behaviour. In addition, it would be illuminating to measure psychological indices and physiological parameters related to autonomic nervous system activation in conjunction with unequal status and female gaze behaviour. This additional research would go some way towards elucidation of the biological mechanisms involved.

\section{REFERENCES}

Abbott, D.H., Keverne, E.B., Bercovitch, et al. (2003). Are subordinates always stressed? A comparative analysis of rank differences in cortisol levels among primates. Hormones and Behavior, 43, 67-82. DOI

Al-Dujaili, E.A.S., \& Sharp, M.A. (2012). Female Salivary Testosterone: Measurement, Challenges and Applications. In: Sergej, M. Ostojic (Ed.), Steroids - From Physiology to Clinical Medicine (pp.129-167). Croation, InTech. DOI

Alliende, M.E. (2002). Mean versus individual hormonal profiles in the menstrual cycle. Fertility and Sterility, 78(1), 90-95. DOI 
Sharp M.A. \& Hamilton G.E.: Female Gaze Behaviour, Status and the Menstrual Cycle Human Ethology Bulletin 32 (2017)1- Proc. of the XXIII Biennial ISHE Congress: 29-41

Bateman, A.J. (1948). Intra-sexual selection in drosophila. Heredity, 2, 349-368. DOI

Bjorkqvist, K., Lagerspetz, K.M.J., \& Kaukiainen, A. (1992). Do girls manipulate and boys fight? Developmental trends in regard to direct and indirect aggression. Aggressive Behavior, 18, 117-127. DOI

Blanchard, D.C., Sakai, R.R., \& McEwen, B. (1993) Subordination stress: Behavioral, brain, and neuroendocrine correlates. Behavioral Brain Research, 58, 113-121. DOI

Boissy, A., \& Bouissou, M.F. (1994). Effects of androgen treatment on behavioral and physiological responses of heifers to fear-eliciting situations. Hormones and Behavior, 28(1), 66-83. DOI

Brewer, M.B., \& Caporael, L.R. (1990). Selfish genes vs. selfish people: Sociobiology as origin myth. Motivation and Emotion, 14, 237-243. DOI

Buser, T. (2012). The impact of the menstrual cycle and hormonal contraceptives on competitiveness. Journal of Economic Behaviour and Organisation, 83, 1-10. DOI

Buss, D.M. (2014) Evolutionary Psychology: The New Science Of The Mind. (5th Edition). United States Of America: Routledge. Psychology Press.

Campbell, A. (1999). Staying alive: evolution, culture and women's intrasexual aggression. Behavioral and Brain Sciences, 22, 203-252. DOI

Campbell, A. (2004). Female competition: Causes, constraints, content, and contexts. Journal of Sex Research, 41(1), 16-26. DOI

Cashdan, E. (2004). Why female hierarchies are less stable. Proceedings of the Human Behavior and Evolution Society, Berlin.

Clutton-Brock, T.H., \& Harvey, P.H. (1977). Primate ecology and social organization. Journal of Zoology, 183, 1-39. DOI

Cobey, K.D., Klipping, C., \& Buunk, A.P. (2013). Hormonal contraceptive use lowers female intrasexual competition in pair-bonded women. Evolution and Human Behavior, 34(4), 294-298. DOI

Cobey K.D., Nicholls M., Leongómez J.D., \& Roberts S.C. (2015). Self-reported dominance in women: Associations with hormonal contraceptive use, relationship status, and testosterone. Adaptive Human Behavior and Physiology, 1, 449-459. DOI

Conway, C.A., Jones, B.C., DeBruine, L.M., Welling, L.L.M., Law Smith, M.J., \& Perrett, D.I. (2007). Salience of emotional displays of danger and contagion in faces is enhanced when progesterone levels are raised. Hormones and Behaviour, 51, 202-206. DOI

Cosmides, L., \& Tooby, J. (1987). From evolution to behavior: Evolutionary psychology as the missing link. In J. Dupre (Ed.), The latest on the best: Essays on evolution and optimality. Cambridge, MA: MIT Press.

Creel, S. (2001). Social dominance and stress hormones. Trends in ecology \& evolution, 16(9), 491-497. DOI

Darwin, C. (1871). The descent of man, and selection in relation to sex. (ed. John Murray) London.

de Waal, F.B.M. (1986). The integration of dominance and social bonding in primates. The Quarterly Review of Biology, 61(4), 459-479. DOI

Daly, M., \& Wilson, M. (1983). Sex, Evolution and Behaviour. PWS; 2nd Revised edition. 
Sharp M.A. \& Hamilton G.E.: Female Gaze Behaviour, Status and the Menstrual Cycle Human Ethology Bulletin 32 (2017)1- Proc. of the XXIII Biennial ISHE Congress: 29-41

Dovido, J.F., Brown, C.E., Heltman, K., Ellyson, S.L., \& Keating, C.F. (1988) Power displays between woman and men in discussions of gender-linked tasks: A multichannel study. Journal of Personality and Social Psychology, 55, 580-587. DOI

Dunbar, R.I.M. (1988). Primate social systems. Ithaca, NY: Cornell University Press. DOI

Ellis, L. (1995). Dominance and reproductive success among nonhuman animals. Ethology and Sociobiology, 16, 257-333. DOI

Emery, N.J. (2000). The eyes have it: the neuroethology, function and evolution of social gaze. Neuroscience \& Biobehavioral Reviews. 24(6), 581-604. DOI

Fausto-Sterling, A. (1992). Myths of Gender: Biological theories about women and men. New York: Basic Books.

Foulsham, T., Cheng, J.T., Tracy, J.L., Henrich, J., \& Kingstone, A. (2010) Gaze allocation in a dynamic situation: Effects of social status and speaking. Cognition, 117, 319-331. DOI

Frauendorfer, D., Schmid-Mas, M., Sanchez-Cortes, D., \& Gatica-Perez, D. (2014). Emergent Power Hierarchies and Group Performance. International Journal of Psychology. 50(5), 392-396. DOI

Gangestad, S. W., Simpson, J. A., Cousins, A. J., Garver-Apgar, C. E., \& Niels Christensen, P. (2004). Women's Preferences for Male Behavioral Displays Change Across the Menstrual Cycle. Psychological Science, 15(3), 203-207. DOI

Geary, D.C. (2010). Male, Female. The Evolution of Human Sex Differences. APA Press, Washington, DC. DOI

Gilbert, F. (1993). Defense and safety: Their function in social behaviour and psychopathology. British Journal of Clinical Psychology, 32(13), 1-154. DOI

Gilligan, C. (1982). In a different voice: Psychological theory and women's development. Cambridge, MA: Harvard University Press.

Goymann, W., \& Wingfield, J.C. (2004). Allostatic load, social status and stress hormones: the costs of social status matter. Animal Behaviour, 67(3), 591-602. DOI

Grant, V.J. (1994). Maternal dominance and the conception of sons. Journal of Medical Psychology, 67, 343-351. DOI

Guay, A.T. (2001). Advances in the management of androgen deficiency in women. Medical Aspects of Human Sexuality, 1, 32-8.

Gowaty, P.A. (1992). Evolutionary Biology and Feminism. Human Nature, 3(3), 217-249. DOI

Gowaty, P.A. (1997). Feminism and Evolutionary Biology - Boundaries, Intersections and Frontiers. New York: Chapman and Hill.

Guay, A.T. (2002). Screening for androgen deficiency in women: methodological and interpretative issues: The Princeton consensus statement on definition, classification, and assessment. Fertility and Sterility, 4(Suppl. 4), 83-88. DOI

Harper, R.C. (1985). Power, dominance and nonverbal behaviour:An overview. In S. L. Ellyson, \& J. F. Dovidio (Eds.). Power, dominance and nonverbal behavior. New York: SpringerVerlag.

Hawley, P.H. (1999). The Ontogenesis of Social Dominance: A Strategy-Based Evolutionary Perspective. Developmental Review, 19, 97-132. DOI 
Sharp M.A. \& Hamilton G.E.: Female Gaze Behaviour, Status and the Menstrual Cycle Human Ethology Bulletin 32 (2017)1- Proc. of the XXIII Biennial ISHE Congress: 29-41

Hayhoe, M., \& Ballard, D. (2005) Eye movements in natural behaviour. Trends in Cognitive Sciences, 9(4), 188-194. DOI

Herbert, T.B., \& Cohen, S. (1993). Stress and immunity in humans: a meta-analytic review. Psychosomatic Medicine, 55, 364-379. DOI

Hermans, E.J., Ramsey, N.F., \& van Honk, J. (2008). Exogenous testosterone enhances responsiveness to social threat in the neural circuitry of social aggression in humans. Biological Psychiatry, 63, 263-270. DOI

Hodge, S.J., Manica, A., Flower, T.P., \& Clutton-Brock, T.H. (2008). Determinants of reproductive success in dominant female meerkats. Journal of Animal Ecology, 77, 92-102. DOI

Hrdy, S. (1999). The Woman That Never Evolved. (revised edition). Cambridge, MA: Harvard University Press.

Hrdy, S. (2009). Mothers and Others: The Evolutionary Origins of Mutual Understanding. Cambridge: Harvard University Press.

Kemper, T.D. (1990). Social structure and testosterone: Explorations of the socio-bio-social chain. New Brunswick: Rutgers University Press.

Koch, S.C., Bachne, C.G., Kruse, L., Zimmerman, F., \& Zumbach, J. (2010). Visual Dominance and Visual Egalitarianism: Individual and Group-Level Influences of Sex and Status in Group Interactions. Journal of Non Verbal Behaviour, 34, 137-153. DOI

Kuzawa, C.W., Gettler, L.T., Huang, Y.Y., \& McDade, T.W. (2010). Mothers have lower testosterone than non-mothers: Evidence from the Philippines. Hormones and Behavior, 57(4), 441-447. DOI

Langton, S.R.H., O'Malley, C., \& Bruce, V. (1996). Actions speak no louder than words: Symmetrical cross-modal interference effects in the processing of verbal and gestural information. Journal of Experimental Psychology: Human Perception and Performance, 22, 1357-1375. DOI

Lamb, T. A. (1986) The familiarity effect in small group hierarchy research. Journal of Social Psychology, 126, 51-56. DOI

Lazarus, R.S., \& Folkman, S. (1984). Stress, appraisal, and coping. Springer publishing company.

Leffler, A., Gillespie, D. L., \& Conaty, J. C (1982). The Effects of status differentiation on nonverbal behaviour. Social Psychology Quarterly, 45(3), 153-161. DOI

Lübke, K., \& Pause, B.M. (2014). Sex-hormone dependent perception of androstenone suggests its involvement in communicating competition and aggression. Physiology and Behaviour, 123, 136-141. DOI

Macrae, C.N., Alnwick, K.M., Milne, A.B., \& Schloerscheidt, A.M. (2002). Person perception across the menstrual cycle: hormonal influences on social-cognitive functioning. Psychological Science, 13, 532-536. DOI

Masataka, N. \& Shibasaki, M. (2012) Premenstrual enhancement of snake detection in visual search in healthy women. Scientific Reports, 2, 1-4. DOI

Mazur, A. (2005). Biosociology of Dominance and Deference. Unites States of America. Rowman and Littlefield Publishers Inc. 
Sharp M.A. \& Hamilton G.E.: Female Gaze Behaviour, Status and the Menstrual Cycle Human Ethology Bulletin 32 (2017)1- Proc. of the XXIII Biennial ISHE Congress: 29-41

Mazur, A., Rosa, E., Faupel, M., Heller, J., Leen, R \& Thurman, B. (1980) Physiological aspects of communication via mutual gaze. American Journal of Sociology, 86, 50-74. DOI

Mazur, A. (1973). A cross-species comparison of status in small established groups. American Sociological Review, 38(5), 513-530. DOI

Mazur, A. \& Booth, A. (1998). Testosterone and dominance in men. Behavioural and Brain Sciences, 21, 353-397. DOI

Penton-Voak, I. S., \& Perrett, D. I. (2000) Female preferences for male faces changes cyclically: Further evidence. Evolution and Human Behaviour, 21, 39-48. DOI

Piccoli, V., Foroni, F., \& Carnaghi, A. (2013). Comparing Group Dehumanization and IntraSexual Competition Among Normally Ovulating Women and Hormonal Contraceptive Users. Personality and Social Psychology Bulletin, 39(12), $1600-1609$. DOI

Pusey, A., Williams, I., \& Goodall, J. (1997). The influence of dominance rank on the reproductive success of female chimpanzees. Science, 277, 828-31. DOI

Ridgeway, C \& Diekema, D. (1989) Dominance and Collective hierarchy formation in male and female task groups. American Sociological Review, 54(1), 79-93. DOI

Rivera, R., Yacobson, I. \& Grimes, D. (1999) The mechanism of action of hormonal contraceptives and intrauterine contraceptive devices. American Journal of Obstetrics and Gynecology, 181, 1263-1269. DOI

Sade, D.S. (1973). An ethogram for Rhesus monkeys. Antithetical contrasts in posture and movement. American Journal of Physical Anthropology, 38, 537-542. DOI

Salvador, A., Suay, F., Gonzalez-Bono, E., \& Serrano, M.A. (2003). Anticipatory cortisol, testosterone and psychological responses to judo competition in young men. Psychoneuroendocrinology, 28, 364-375. DOI

Sapolsky, R.M., (1982). The endocrine stress-response and social status in the wild baboon. Hormones and. Behavior. 15, 279-292. DOI

Sapolsky, R.M., (2002). Endocrinology of the stress-response. In: Becker, J., Breedlove, S., Crews, D., McCarthy, M. (Eds.), Behavioral Endocrinology 2nd edition (pp.409-450). MIT Press, Cambridge, MA.

Schmid Mast, M. (2001). Gender differences and similarities in dominance hierarchies in samesex groups based on speaking time. Sex Roles, 44, 537-556. DOI

Schmid Mast, M. (2002). Female Dominance Hierarchies: Are They Any Different From Males? Personality and Social Psychology Bulletin, 28(1), 29-39. DOI

Schultheiss, O.C., Campbell, K.L., \& McCelland, D.C. (1999). Implicit power motivation moderates men's testosterone responses to imagined and real dominance success. Hormones and Behavior, 36, 234-241. DOI

Setchell, J. M., \& Wickings, E. J. (2005) Dominance, status signals and coloration in male mandrills (Mandrillus sphinx). Ethology, 111, 25-50. DOI

Taylor, S.E., Klein, L.C., Lewis, B.P., et al., (2000). Biobehavioral responses to stress in females: Tend-and-befriend, not fight-or-flight. Psychological Review, 107, 411-429. DOI

Tiger, L. \& Fowler, H.T. (Eds.) (2007). Female Hierarchies. Transaction Publishers, New Brunswick. 
Sharp M.A. \& Hamilton G.E.: Female Gaze Behaviour, Status and the Menstrual Cycle Human Ethology Bulletin 32 (2017) 1- Proc. of the XXIII Biennial ISHE Congress: 29-41

Van Anders, S. M., \& Watson, N. V. (2006). Relationship status and testosterone in North American heterosexual and non-heterosexual men and women: cross-sectional and longitudinal data. Psychoneuroendocrinology, 31(6), 715-23. DOI

van Honk, J., Tuiten, A., Verbaten, R., van den Hout, M., Koppeschaar, H., Thijseen, J., \& de Haan, E. (1999) Correlations among salivary testosterone, mood, and selective attention to threat in humans. Hormones and Behaviour, 36, 17-24. DOI

Wasser, S.C., \& Barash, D. (1984). Reproductive suppression among female mammals. Quarterly Review of Biology, 58(4), 513-538. DOI

Wicker, F.W., Payne, G.C., \& Morgan, R.D. (1983). Participant descriptions of guilt and shame. Motivation and Emotion, 7, 25-39. DOI

Wittig, R.M. \& Boesch, C. (2003) Food Competition and Linear Dominance Hierarchy among Female Chimpanzees of the Tai National Park. International Journal of Primatology, 24(4), 847-867. DOI

Zimmerman, Y. et al. (2015). Restoring testosterone levels by adding dehydroepiandrosterone to a drospirenone containing combined oral contraceptive: endocrine effects. Contraception, 91(2), 127-133. DOI 